\title{
BÉLANGER, René, Les Basques dans l'estuaire du \\ Saint-Laurent. Les Presses de l'Université du Québec, \\ Montréal, 1971. 0,240 x 0,175 m., 162 p. \$5.80.
}

\section{Lucien Campeau}

Volume 25, numéro 3, décembre 1971

URI : https://id.erudit.org/iderudit/303098ar

DOI : https://doi.org/10.7202/303098ar

Aller au sommaire du numéro

Éditeur(s)

Institut d'histoire de l'Amérique française

ISSN

0035-2357 (imprimé)

1492-1383 (numérique)

Découvrir la revue

Citer ce compte rendu

Campeau, L. (1971). Compte rendu de [BÉLANGER, René, Les Basques dans l'estuaire du Saint-Laurent. Les Presses de l'Université du Québec, Montréal, 1971. 0,240 x 0,175 m., 162 p. \$5.80.] Revue d'histoire de l'Amérique française, 25(3), 409-410. https://doi.org/10.7202/303098ar 
BÉLANGER, René, Les Basques dans l'estuaire du Saint-Laurent. Les Presses de l'Université du Québec, Montréal, 1971. $0,240 \times 0,175$ m., 162 pages. $\$ 5.80$.

Volume dont la présentation agréable, la claire impression, le style alerte, non moins que l'information originale, sauront charmer le lecteur. L'A. a principalement fait sa recherche dans les archives basques et espagnoles, peu connues de nos historiens. Il s'est intéressé à un sujet demeuré jusqu'ici obscur. On lui saura gré des lumières qu'il apporte. Peut-être la matière ne le permettait-elle pas, mais nous aurions préféré un traitement plus chronolog que de ce thème, auquel l'A. a donné une ordonnance de caractère géographique. La suite et les péripéties de l'histoire sont moins en relief. Mais c'est un livre estimable, qu'on lira avec plaisir et profit.

Voici quelques remarques que la lecture a suscitées. Certaines d'entre elles ne seront que matière d'opinion et souffriront facilement le désaccord. Nous ne voyons pas que Cartier ait rencontré des baleiniers basques dans le fleuve ( $\mathrm{p}$. 36), lors de son deuxième voyage. Il est plus que probable que les Basques ont fait assez tôt ( $c a$ 1530) la pêche de la morue sur la côte orientale de Terre-Neuve, puis au détroit de Belle-Isle, mais à la su te des Portugais, des Normands et des Bretons. Quand une partie d'entre eux se sont-ils spécialisés dans la chasse aux baleines, dont la poursuite les a conduits jusqu'au Saguenay? Les sources dignes de confiance paraissent présentement indiquer le milieu du siècle comme le commencement de ce mouvement, qui s'intensifiera peu à peu. La pénétration basque dans le Saint-Laurent semble avoir atteint son apogée après l'éviction des Espagnols par les Anglais de la côte orientale de Terre-Neuve, au temps des guerres de l'Angleterre contre Philippe II. La politique française des monopoles commerciaux, la colonisation du Saint-Laurent, probablement aussi quelque autre facteur, provoqueront la cessation de cette exploitation par les Basques.

C'est en venant au Canada, non en retournant en France (p. 53), que les Jésuites ont fait naufrage à Canso en 1629. La baie de Savalette, dont parlent Lescarbot et Champlain, n'est pas la baie de Chedabouctou (p. 57), mais plutôt Tor Bay, en Nouvelle-Ecosse. Plaisance est un nom bien français qui a précédé les Basques ( $p$. 58) et Ronhoso (Rognouse) est sans hésitation un nom portugais. Le P. Charles Lalemant ne dit pas que le castor valait une pistole pièce à Tadoussac (p. 66): ce serait exorbitant. C'était le prix du castor en France. Que le commerce des fourrures ait été la cause de l'expulsion des Iroquois hors de la vallée du Saint-Laurent, ce n'est qu'une hypothèse vraisemblable (p. 67). Si le grand dérangement a eu lieu vers 1550 , comme on croit, sa valeur explicative n'est pas forte.

Il est possible que le basque ait influencé les langues indigènes (p. 86). A ce compte, le français et l'anglais l'ont fait encore plus. Il devait y avoir entre Indiens et Basques, comme entre Indiens et Français, un jargon mi-indien, mi-basque, qui servait de langue de communication. Au début, les interprètes français qui se vantaient de savoir les langues ne parlaient 
guère qu'un baragoin semblable. Il est vrai, toutefois, qu'un mot comme orignal nous vient en droite ligne du basque.

L'ouvrage est orné de gravures, de cartes, de dessins et de photos de documents: le tout bien choisi. Les sources publiées et traduites par l'A. à la suite du texte sont intéressantes. On trouvera aussi avantage à consulter les appendices et la bibliographie. Il n'y a pas d'index analytique, mais l'ouvrage est peu considérable et on s'y retrouve facilement.

Saint-Jérôme

LUCIEN CAMPEAU 